Finisterra, XXXVII, 73, 2002, pp. 61-80

\title{
NOVOS DESAFIOS E ORIENTAÇÕES DAS POLÍTICAS CULTURAIS: TENDÊNCIAS NAS DEMOCRACIAS DESENVOLVIDAS E ESPECIFICIDADES DO CASO PORTUGUÊS ${ }^{1}$
}

\author{
Eduardo BRito HenRiques ${ }^{2}$
}

\begin{abstract}
Resumo - Nos dois últimos decénios do século XX, as sociedades democráticas desenvolvidas passaram por um conjunto de alterações que envolveram não só mudanças no plano económico, como também no plano societal e político. Uma das mais estimulantes teorias desenvolvidas com o intuito de explicar essas mudanças foi a que desenvolveu a escola regulacionista francesa, teoria essa que aliás tem tido grande acolhimento e tem sido usada na interpretação de numerosos aspectos das sociedades contemporâneas, sobretudo dos que se articulam mais directamente com a economia.

Neste artigo, analisa-se um aspecto das transformações ocorridas na esfera política que não tem até à data merecido grande atenção: as mudanças nas políticas culturais. $\mathrm{O}$ ensaio que se publica procura primeiro diagnosticar as principais alterações observadas neste campo e verificar até que ponto também estas podem afinal ser interpretadas à luz do quadro teórico a que se aludiu. Finalmente, observam-se as especificidades que neste capítulo o caso português encerra e procuram interpretar-se essas particularidades tendo em conta a condição semiperiférica do país.
\end{abstract}

Palavras-chave : Políticas culturais, Estado-Providência, crise do fordismo, neoliberalismo, Portugal.

Abstract - NEW CHALlENGES AND TENDENCIES IN CULTURAL POLICIES: TRENDS IN DEVELOPED DEMOCRACIES AND PoRTuguese SPECIFICITIES - In the last twenty years of the 20th century, a vast range of interrelated changes took place in the most developed democratic societies, and their effects were felt in the economic as well as in the societal and political areas. One of the most successful theoretical frameworks used since then to interpret and explain all these changes has been the French regulationist school theory.

\footnotetext{
1 Investigação apoiada pelo projecto «Repensar Portugal na Europa. Perspectivas de um país periférico» (PRAXIS XXI 2/2.2/MAR/1743/95).

2 Assistente da Faculdade de Letras, Universidade de Lisboa. Investigador do Centro de Estudos Geográficos. E-mail: eduardo.b.h@mail.doc.fl.ul.pt
} 
This paper addresses a neglected issue in recent political, sociological and geographical studies on the post-Fordist transition in the more developed democratic societies: changes in cultural policies. After identifying the main changes in this area, this paper examines whether the changes that have occurred in cultural policies since mid-80s agree with what could be the cultural logic of a supposedly post-Fordist state, as the French regulationist theory sustains. Lastly, Portuguese specificities in this domain are explored and interpreted in the light of the semi-peripheral condition of the country.

Key words : Cultural policies, welfarism, post-Fordist crisis, neoliberalism, Portugal.

\section{A CULTURA COMO OBJECTO DA INTERVENÇÃO DO ESTADO NAS DEMOCRACIAS DESENVOLVIDAS}

Não é de agora o envolvimento (alguns preferirão falar de ingerência) das instituições de poder, e particularmente do Estado, nas artes e na cultura. A criação de teatros, bibliotecas e museus nacionais, instituições que na Europa remontam aos séculos XVII e XVIII, estão entre as medidas de política concretas que mais cedo se definiram para esta área e onde primeiro se sentiu a assunção por parte do Estado de uma responsabilidade em matéria cultural. Outras das medidas mais antigas são as acções em prol da salvaguarda do património histórico, difundidas no século XIX, em correlação com o processo de construção dos Estados-Nações modernos. Datam de então a publicação das primeiras leis e regulamentos para a salvaguarda dos monumentos, assim como a criação de organismos, financiados pelo erário público, para a sua inventariação e conservação.

O século Xx levaria bem mais longe a influência do Estado na área das artes e da cultura, com dois modelos fundamentais de políticas culturais.

Por um lado, as experiências totalitárias dos regimes fascistas (fascistas propriamente ditos e afins) e comunistas, que a partir do segundo quartel do século procuram fazer uma tutela 'musculada' da criação artística e orientá-la com intuitos propagandistas e ideológicos. Conhecem-se os meios radicais que esta política empregava: colocar à disposição dos autores eleitos meios que chegavam a ser generosos, e ao mesmo tempo perseguir, isolar, e até mesmo exterminar os autores proscritos e a arte dita degenerada...

A outra experiência de política cultural, baseada também numa intervenção forte do Estado, mas com outros intuitos e estratégias, é a que se forma nas sociedades democráticas e desenvolvidas no pós-guerra. Sustentado pela doutrina económica keynesiana, difunde-se e consagra-se neste período, sobretudo a partir dos anos 60, o paradigma de um Estado interventor na economia, preocupado com o problema do pleno emprego, e também na esfera social, ou seja, com responsabilidades claras e assumidas na redistribuição dos rendimentos, em matéria assistencial e na criação de condições de bem-estar. Disto resul- 
tou que o Estado tenha chamado a si, mais que nunca até então, tanto em regimes sociais-democratas como conservadores, a provisão de numerosos bens e serviços, desde a energia à saúde, dos transportes à educação. No mesmo espírito, alargou-se a intervenção em matéria cultural, com consequências num crescimento gradual mas rápido das despesas públicas nas artes e na cultura, fenómeno que passou a ser observável até mesmo em países com fraca tradição de intervenção pública como os EUA ${ }^{3}$.

Como refere EsPING-ANDERSEN (1990: 1), o conceito de Estado-Providência pode ser apreendido em diferentes acepções. No seu sentido mais estrito - que é também o mais corrente - o conceito diz basicamente respeito ao papel decisivo que o Estado passou a ter, a partir do terceiro quartel do século Xx (embora em alguns países mais cedo), no 'terrain of social amelioration' (ibid.), ou seja nos aspectos que se prendem com a política social, a assistência em caso de doença, etc. Na sua acepção mais lata, o conceito é passível de ser aplicado também à crescente intervenção do Estado em outros domínios, da política económica à habitação ou aos transportes, já que grande parte dessa intervenção passou a ser legitimada, sensivelmente desde a mesma altura, pela necessidade de assegurar direitos sociais e garantir bem-estar. É esta leitura alargada do welfarism que tem levado alguns autores a entenderem o aumento do apoio público à cultura nas democracias desenvolvidas após os anos 60 como uma inerência ou algo estreitamente relacionado com o próprio desenvolvimento do Estado-Providência (Zimmer e ToEPler, 1996).

O crescimento dos gastos públicos e o modo como se exerceu a participação do sector público na cultura não foi uniforme nas várias democracias que evoluíram para Estados-Providência. O quadro institucional específico, a tradição mais ou menos liberal, ou mais ou menos centralista de cada um dos países, assim como a orientação política dos diferentes governos, produziram diferenças sensíveis, neste como noutros domínios. É aliás sabido que não existe nem existiu jamais uma forma única de Estado-Providência, mas sim diferentes tipos dentro de uma mesma grande família de regimes, uns de orientação mais social-democrata, como os escandinavos, outros mais liberais, como os anglosaxónios, outros mais conservadores, como o francês ou alemão ${ }^{4}$.

Mas não é por as soluções encontradas em França ou nos EUA para o apoio público à cultura diferirem entre si, ou do grau de envolvimento do Estado ser num caso maior que noutro, que o princípio de base ou a filosofia que as sustenta são diferentes. As diferenças, que nos dois casos citados se traduzem num maior peso do papel do Estado em França e numa intervenção mais indirecta, sobretudo por via fiscal, nos EUA, decorrem de em cada um destes dois

3 Cf. Netzer (1978), que constitui a primeira análise detalhada da evolução das políticas culturais e das despesas públicas com a cultura nos EUA.

4 Cf. Esping-Andersen (1990) onde, com base numa análise multivariada das despesas públicas e da elegibilidade dos indivíduos aos serviços públicos em 18 países da OCDE, se chega à tipologia descrita e se formula a tese dos três modelos de Estado-Providência. 
países persistirem tradições políticas muito distintas, uma mais centralista, aristocrática e racionalista, e a outra mais liberal, burguesa e republicana, como sustentaram Zimmer e ToEPleR (1999). Sob essas diferenças encontram-se porém, no essencial, os mesmos argumentos, sendo as razões que levaram à criação em França, em 1959, do primeiro ministério da cultura, comparáveis às que justificaram o aparecimento nos EUA do National Endowment for the Arts NEA, em 1965.

Esses argumentos são em primeiro lugar de natureza económica. A justificação para o financiamento ou subvenção das artes pelo Estado procurou sempre encontrar uma base de apoio sólida, aparentemente irrefutável, na economia, ora na ideia de que há no mercado cultural falhas que é necessário corrigir, ora na de que as artes e a cultura configuram bens especiais com benefícios sociais superiores aos benefícios privados, e que por isso merecem ser tutelados ou apoiados pelo sector público.

Um dos argumentos mais recorrentes vem do campo da micro-economia e é dado pela lei de Baumol-Bowen, cuja formulação se deve a dois economistas norte-americanos que em meados dos anos 60 estudaram o sector das artes performativas ${ }^{5}$. Contrariamente a outros sectores da economia, onde é possível introduzir inovações tecnológicas e, por esta via, produzir ganhos de produtividade, sustenta esta lei que no sector das artes, e particularmente no das artes do espectáculo, essa possibilidade não existe, ou é limitada. É igualmente inviável pensar em reduzir o factor trabalho ou aumentar por outras formas a produção por unidade de tempo. Não sendo portanto possível pensar em ganhos de produtividade, e sendo os salários determinados pelo sector mais dinâmico da economia, diz a lei que se gera nestas actividades um desequilíbrio entre a necessidade de aumentar os salários e a possibilidade técnica de garantir esses aumentos, o que a prazo, sem se introduzirem subsídios, levaria à extinção do sector ${ }^{6}$.

Outro argumento comum para defender o apoio público às artes e à cultura é o de que os produtos da actividade artística e cultural constituem aquilo a que a economia chama bens meritórios (merit goods). Deste ponto de vista, tratar-se-iam de bens de bondade intrínseca, com benefícios para os indivíduos superiores aos que estes são capazes de neles reconhecer, uma vez que, para além da utilidade que decorre do bem-estar que proporcionam, teriam ainda virtudes em termos da própria formação e valorização pessoal, um pouco à semelhança da educação, ou até da higiene. Como qualquer bem meritório, as artes e a cultura não teriam um valor de mercado consentâneo com o seu valor intrínseco, na medida em que nem todos os indivíduos avaliam correctamente os benefícios, privados e sociais, que deles decorrem. Competiria assim ao Estado zelar pelo

5 Ver, por exemplo, RAussel Köster (1999: 101 e seguintes), onde se apresenta com algum detalhe a lei de Baumol-Bowell e se faz uma resenha das principais críticas que lhe têm sido dirigidas.

6 A aplicação da lei de Baumol-Bowen a todo o sector cultural é abusiva. As limitações aos aumentos de produtividade no teatro, por exemplo, não são comparáveis às que afectam o cinema. 
seu usufruto e desenvolver mecanismos que assegurassem uma difusão o mais alargada possível destes bens e serviços ${ }^{7}$.

Outra razão que frequentemente se aponta para o Estado chamar a si a tutela da cultura, ou apoiar as actividades com ela relacionadas, reside em as artes, as letras, o património, etc., poderem ser assimilados ao conceito de bem público. Os bens públicos, por definição, não podem ser afectados a privados. São bens geradores de benefícios muito latos que o mercado não é capaz por si só de remunerar. A utilidade que um indivíduo deles retira não diminui a utilidade que deles retiram outros indivíduos; assim constituem algo que a todos pertence, ou de que qualquer um deve poder fruir em iguais condições. $\mathrm{O}$ princípio parece portanto ser aplicável, como se perceberá, não apenas aos grandes monumentos históricos, ao património móvel dos museus, mas também às obras musicais e literárias (à obra em si, e não ao concerto como evento ou ao livro como objecto). Assim sendo, a intervenção do Estado justificar-se-ia uma vez que, retirando todos os indivíduos benefícios potenciais da conservação do património, ou da criação artística, parece justo que o colectivo financie pelo menos em parte serviços que de outra forma só alguns pagariam (os que visitam museus ou assistem a concertos...), mas que se encontram à disposição de todos e de que todos potencialmente podem beneficiar.

O último argumento económico é o das externalidades positivas. Com isto não se pretende apenas aludir aos benefícios pecuniários que decorrem, por exemplo, dos gastos de turistas e visitantes atraídos pelas artes e cultura, mas também ao facto da riqueza e diversidade da oferta cultural funcionar hoje em dia como 'factor de localização imaterial' para muitas actividades, sobretudo para as de mão-de-obra mais qualificada. Estes benefícios extravasam para toda a comunidade, tanto para os apreciadores e consumidores das artes como para os que não o são. Neste sentido resulta defensável que o ónus da sua manutenção e reprodução não possa ou não deva ser imputado a um ou a outro agente económico em particular, mas assegurado pelo Estado ou, em sentido mais lato, pelo sector público (regiões, municípios, etc.).

Para além destes vários argumentos de natureza económica, que não são absolutamente impolutos, que como quaisquer outros são susceptíveis de discussão, mas que mais ou menos serviram durante anos, quase sem crítica, para justificar a opção do Estado (e nomeadamente do Estado-Providência, no sentido mais lato do conceito) em incluir a cultura entre as suas alargadas competências, há dois outros, não menos fortes, de carácter político e ideológico.

7 Cf. GRAMPP (1991: 237 e seguintes), economista de orientação liberal que se tem dedicado ao estudo das artes, faz uma crítica bem humorada deste princípio. Pergunta-se GRAMPP se, de acordo com esta óptica, não deveria o Estado ir mais longe no seu apoio às artes (que afinal parece ser apoio aos consumidores...) e impor o consumo obrigatório de ópera como se faz com a educação ou as vacinas, ainda que isso vá contra a vontade dos indivíduos, ou criar prémios para os que frequentam espectáculos e museus como medida de estímulo. 
Um pode considerar-se tradicional, no sentido em que é antigo. Vem do século XIX e em rigor tem mais que ver com o projecto do Estado-Nação do que propriamente com o do Estado-Providência ${ }^{8}$. Trata-se da ideia segundo a qual compete ao Estado proteger a cultura como forma de salvaguarda da própria identidade nacional, responsabilidade que se aceita de forma mais ou menos consensual e que constitui, de resto, uma função vital do próprio Estado, porquanto a sua concepção moderna se funda justamente na ideia da nação como identidade colectiva e soberana.

A outra justificação político-ideológica para a intervenção do Estado na cultura, e que, como a anterior, acabou por orientar as opções que se tomaram em matéria de política cultural, tem que ver com o modelo de sociedade democrática e justa, tendencialmente igualitária, que servia de paradigma ou estava subjacente ao projecto do Estado-Providência. Assumindo-se a equidade da participação dos cidadãos na vida cultural como uma meta do desenvolvimento da sociedade, caberia ao Estado desenvolver os esforços necessários nesse sentido.

Todas estas razões convergiram para que, como dissemos, sobretudo a partir de 1960, as despesas públicas com a cultura tenham registado um rápido aumento nos países mais desenvolvidos. Tomando como exemplo a Suécia, verifica-se que o valor das subvenções do Estado para as actividades culturais aumentou $187 \%$ entre 1960 e 1970 (preços constantes), e cerca de 98\% entre 1970 e 1980 (KleBERG, 1992: 102). Na França, o ministério da cultura, que constitui hoje uma pesadíssima máquina administrativa com cerca de 16000 funcionários, viu aumentado o seu orçamento numa proporção praticamente de 1 para 7 entre 1959 e os finais dos anos 80 (Zimmer e ToePler, 1999: 37). Até mesmo nos EUA, onde a prática dominante no financiamento da cultura sempre foi a do mecenato privado, assistimos nos anos 60 à criação de um organismo federal - o NEA - responsável pela prestação de apoio financeiro às diversas agências estaduais e locais de apoio às artes - as State Arts Agencies (SAA) e as Local Arts Agencies (LAA), na sua maioria constituídas por organismos independentes do sector privado não-lucrativo, competindo-lhe ainda premiar com bolsas projectos apresentados por instituições artísticas e culturais privadas que se distinguissem pela sua excelência (Zimmer e ToEPler, 1996; MulcaHY, 1997).

No seu propósito múltiplo de salvaguardar a identidade nacional, de colmatar as deficiências da economia de mercado no sector específico das artes e de garantir igualdade de oportunidades de acesso à vida cultural por parte de todos os cidadãos, alargou-se o domínio de intervenção do Estado, que passou a cobrir desde a chamada 'alta cultura' ou 'cultura cultivada' até à cultura popular e à cultura de massas (TV, cinema, indústria discográfica, etc.). As estratégias também se diversificaram. Para além da criação de equipamentos, onde continuou a ter um papel decisivo (senão até mais determinante), o Estado passou a

8 Para uma síntese das teorias do nacionalismo e dos estados-nação, cf. SoBRAL (1996). 
estar presente de forma muito mais activa na educação artística e na produção cultural, quer directamente, criando ou chamando a si a gestão e o financiamento de companhias de teatro, companhias de ópera e bailado, orquestras, conservatórios, etc., que na maior parte dos casos passaram a ter um estatuto e um modelo de funcionamento equiparável a qualquer outro organismo do sector público, quer indirectamente, por via da subvenção e apoio a grupos independentes.

Iniciativas como a das maisons de la culture, lançada em França pelo ministro André Malraux nos anos 60, ilustram bem a vontade do Estado em aumentar e melhorar a dotação da população em equipamentos, numa lógica que a certa altura passou a ser também de desconcentração/descentralização, e de, por esta via, garantir maior facilidade de acesso dos cidadãos à vida cultural. Na Suécia, outra forma encontrada para resolver a mesma questão foi a aposta na itinerância, mormente através da criação de um organismo público responsável pela organização de exposições de arte itinerantes - serviço que se revelaria de especial utilidade para as regiões de mais fraca densidade demográfica -, além do apoio e estímulo às associações artísticas e culturais de base local. Mas o caso sueco salienta-se ainda pelo modo lato como o Estado-Providência entendeu o direito à participação na vida cultural, elegendo a educação para as artes e o desenvolvimento da criatividade artística como objectivos básicos da sua política (conservatórios municipais de música parcialmente subsidiados pelo Estado, estímulo à criação e apoio financeiro a associações para a educação artística de adultos, etc.), e também pelo modo como não hesitou sequer em se substituir aos privados, criando em 1963 um instituto público que se tornaria no principal produtor de filmes do país (KLEBERG, 1992).

Nestes dois casos citados, como de resto em muitos outros países, coube ainda ao Estado assumir como nunca antes o papel de Estado-patrono, subvencionando os mais diversos ramos do sector cultural, do livro ao disco, das artes do espectáculo às artes plásticas. A Finlândia terá sido um dos casos em que se levou mais longe e à letra esta missão, ao instituir em 1969 a figura da bolsa para artistas, esquema que no fundo correspondia à criação de postos de trabalho assalariado temporários, pagos pelo Estado, mas de longa duração, podendo estender-se de 1 até 15 anos (IsOHOKANA-AsunmaA, 1996: 58).

\section{NOVAS TENDÊNCIAS DAS POLÍTICAS PÚBLICAS PARA A CULTURA: ABANDONO DE UM PROJECTO OU REDEFINIÇÃO DE ESTRATÉGIAS?}

Na Europa, como aliás em todos os países que desenvolveram formas de Estado-Providência (nos EUA, no Canadá, na Austrália, no Japão, etc.), as artes e a cultura continuam a ser hoje financiadas em parte pelo sector público, e na maioria dos casos até em larga medida. Tal não significa porém que a oportunidade, a pertinência, e inclusivamente a própria legitimidade da intervenção do 
Estado nestas áreas continuem a ser tidas como inquestionáveis, ou pelo menos tão consensuais quanto o eram há alguns decénios atrás.

O debate a respeito destas matérias está na ordem do dia, como aliás está o debate sobre a intervenção do sector público em muitos outros domínios. Razões diversas, em primeiro lugar de natureza económica, têm levantado dúvidas quanto à possibilidade de se continuar uma política intervencionista. E surgem mesmo suspeitas - alargadas mas ainda não unânimes... - quanto às próprias condições de futuro do Estado-Providência, quer se entenda este conceito em sentido estrito, como lato.

A crise dos anos 70 foi o factor que fez despoletar a polémica e que introduziu os primeiros sinais de hesitação na política do Estado-Providência (Mishra, 1984). Uma nova situação económica, não prevista na teoria keynesiana, marcada pela conjugação de baixo crescimento e elevada inflação - a estagflação -, veio colocar em dúvida o paradigma da economia mista, dando força aos argumentos favoráveis a uma menor intervenção do sector público e justificando que tivessem começado a surgir em diversos países, logo nesse decénio, sinais de algum recuo na sua acção (ibid.).

Outro factor (não inteiramente independente) tem que ver com a crise das finanças públicas e os problemas com que se começaram a confrontar os sistemas de protecção social em muitos países desenvolvidos. A ocorrência de elevadas taxas de desemprego resultantes do processo de reestruturação produtiva, juntamente com o envelhecimento da população, tem-se traduzido numa diminuição do peso relativo dos contribuintes líquidos e num aumento complementar dos beneficiários, criando uma situação de desequilíbrio que, para alguns países, num horizonte não muito distante, pode significar o colapso do sistema. A contenção dos gastos públicos revela-se, deste ponto de vista, um imperativo.

Finalmente, no caso específico dos países da UE, há ainda o desafio da união monetária, que produz pressões no mesmo sentido. Um dos critérios de adesão ao euro que os Estados membros se viram obrigados a respeitar nos anos 90 foi precisamente a redução do défice público. Também em consequência disto a contenção das despesas do Estado passou a ser um princípio orientador, e a liberalização da economia, com a desmonopolização de sectores nacionalizados ou estatais e sua consequente privatização, uma solução comum.

Da confluência destes vários factores acabou por resultar que, a partir dos anos 80 , o neoliberalismo se tenha afirmado como uma nova tendência forte da política económica. Uma tendência, aliás, visível às mais diversas escalas, do plano internacional ao local, das novas regras do GATT à privatização dos serviços municipais, passando pela flexibilização do mercado de emprego ${ }^{9}$. Seria todavia nos países onde então se formam maiorias neoconservadoras, como nos EUA ou no Reino Unido, que se tentaria levar mais longe estas orientações e que as suas consequências acabariam por ganhar também maior visibilidade.

9 Muitas destas tendências aparecem sistematizadas em Peck e Tickell (1994: 308-310). 
No caso da cultura, a tendência pró-liberal passou a contar ainda com dois outros argumentos favoráveis a uma menor intervenção do Estado. Por um lado, o argumento libertário, segundo o qual a tutela do Estado e as orientações deste em matéria cultural podem cercear a liberdade da criação artística e só muito raramente traduzem as preferências e as aspirações das massas, reproduzindo em vez disso uma visão elitista da cultura e das artes. Nascido dos movimentos de contestação da nouvelle gauche, este argumento acabaria por colher também, com o tempo, a simpatia dos neoliberais, ganhando aderentes.

Por outro lado, aparece o argumento da ineficácia do Estado na democratização da cultura. Embora sem nunca se discutir ou criticar o princípio de que as sociedades democráticas e desenvolvidas devem ter como projecto ou horizonte a igualdade de oportunidades no acesso à cultura, começam a surgir dúvidas quanto à possibilidade do Estado conseguir cumprir esse desiderato. A experiência de mais de vinte anos de financiamento público das artes e da cultura parece demonstrar com efeito que, embora tendo aumentado os consumos culturais, a participação nas artes continua a ser apanágio das elites - mesmo no estrangeiro -, o que levanta dúvidas quanto à justiça da afectação de recursos de todos (e que são escassos) à satisfação das necessidades de um grupo restrito da população ${ }^{10}$.

Estes vários factores (embora seguramente com preponderância das razões económicas que referimos) conjugaram-se de molde a que, a partir dos anos 80 , na maior parte dos países desenvolvidos, a tendência de evolução das despesas públicas com a cultura conhecesse alterações, estagnando ou até mesmo invertendo-se.

Na Suécia, o crescimento observado nos anos 60 e 70, que foi rápido, é subitamente interrompido com a viragem do decénio (KLEBERG, 1992: 100 e seguintes). De 1980 para 1981, as despesas públicas com a cultura registam pela primeira vez uma ligeira diminuição (considerando preços cons-tantes). Depois, manter-se-iam mais ou menos estáveis ao longo dos anos 80 , com pequenas oscilações interanuais, muito embora continuando a aumentar o seu peso relativo no conjunto das despesas públicas (ibid. $)^{11}$.

Nos Países Baixos, onde a afirmação do Estado-Providência nos decénios de 60 e 70 também havia sido acompanhada por um apoio forte às artes e à cultura, os anos 80 parecem ter sido marcados por uma estagnação (ADAMs, 1994: 58 e seguintes). Entre 1981 e 1988, as despesas do Estado com as artes e a cultura mantiveram-se, grosso modo, constantes (considerando preços fixos), com ligeiras flutuações anuais em torno dos valores do início da década. A única

10 Cf. Mónica (1999), onde se expõem e desenvolvem estes argumentos.

11 Este não é um aspecto de somenos importância. É interessante observar que os cortes ou as restrições aos gastos públicos com a cultura acompanham uma tendência mais geral das despesas públicas, sendo que em certa medida parecem até ser menos drásticos que em outros domínios (de outra forma não se explicaria o reforço do peso relativo da cultura no cômputo dos gastos do Estado). 
excepção foi o ano de 1989, que registou um decréscimo de 31,3\% relativamente ao ano anterior nas verbas do Estado destinadas às artes e à cultura, sobretudo devido à transferência da responsabilidade de gestão e financiamento das bibliotecas da administração central para os municípios. Globalmente, considerando em conjunto as despesas do Estado, das províncias e dos municípios, pode dizer-se que a tendência de evolução das verbas destinadas pelo sector público à cultura foi de suave descida (ibid.).

No caso finlandês, onde a afirmação do Estado-Providência se iniciou comparativamente mais tarde, só em finais dos anos 60 , os anos 80 foram ainda em grande parte marcados por um crescimento apreciável das despesas culturais do Estado (IsoHoKana-AsunmaA, 1996: 120 e seguintes). Na segunda metade do decénio, porém, o ritmo de crescimento dos gastos públicos na área cultural começaria a abrandar, entrando nos anos 90 em estabilização (ibid.).

Os estudos comparativos que conhecemos sobre as mudanças recentes nas políticas culturais das democracias desenvolvidas apontam para outros países como a Alemanha, o Canadá ou os EUA, conclusões algo semelhantes quanto à evolução das despesas públicas (MulCAHY, 1997; Zimmer e ToePler, 1996; id. 1999). A dificuldade em prosseguir o crescimento da ajuda pública, ou até somente em manter os níveis alcançados, é generalizada. Mas não é isto apenas que caracteriza as mudanças em curso nas políticas culturais. Todos os países parecem ter igualmente despertado, de uma forma ou de outra, para a necessidade de encontrar fontes de financiamento alternativas para a cultura, seja no mercado, seja no chamado 'terceiro sector' (ou sector privado não lucrativo), assim como de descobrir novos modelos de gestão para as instituições e serviços culturais estatais, mais flexíveis, de tipo empresarial, norteados por critérios comerciais.

Os governos neoconservadores, da chamada 'nova direita', foram os que procuraram levar mais longe estas mudanças e introduzir fracturas mais profundas na tradição da política cultural. Quer o reaganismo nos EUA, quer o thatcherismo no Reino Unido, produziram duros revezes nessa tradição. Os orçamentos do NEA e do Arts Council (AC) tiveram cortes significativos. Por outro lado, no plano retórico e ideológico, ousaram afrontar o princípio da especificidade dos bens culturais e introduzir no discurso a ideia de que as artes, como qualquer mercadoria, deveriam ter em vista o mercado e estabelecer como meta as audiências, não os subsídios (MUlCAHY, 1997; BuRNS, 1999). Nunca a fractura chegou a ser tão profunda, porém, quanto - pelo menos aparentemente - pretenderam estes regimes: Margaret Thatcher, por exemplo, fracassou diante da opinião pública na sua tentativa de introduzir publicidade na $\mathrm{BBC}$, da mesma maneira que não conseguiu levar a bom termo o projecto de lei que tornaria possível a alienação das obras de arte armazenadas nos museus britânicos.

Em contrapartida, em países com uma tradição menos liberal, seja de influência mais social-democrata, seja de influência mais centralista e estatizante, observam-se nos anos 80 e 90 sinais vários de 'viragem' para o mercado, 
de valorização do financiamento privado, assim como de crescente predominância de critérios comerciais e racionalistas no funcionamento das instituições culturais; e isto tanto sob a acção de governos de direita como de esquerda (CAUST, 1999: 17)...

Poderíamos referir numerosos exemplos dessa viragem. Um dos mais evidentes foi a desmonopolização do sector da TV e a sua liberalização ${ }^{12}$, vaga que nos anos 80, em pouco tempo, varreu os países europeus - França, Alemanha, países escandinavos,... - e que em certa medida foi também algo que antecipou passos posteriores que se dariam noutros sectores, mas no mesmo sentido. Outro exemplo que ressalta é a 'empresarialização' dos serviços culturais, incluindo aqui desde os museus às orquestras e às companhias de teatro e bailado públicas ou subvencionadas, as quais passaram a ser geridas cada vez mais, e num número cada vez maior de países, de acordo com critérios comerciais e com vista ao auto-financiamento (daí, por exemplo, as cafetarias e as lojas dos museus, que tanto peso - e até mesmo alguma autonomia - ganharam dentro dos equipamentos). Igualmente elucidativo é ainda o exemplo das políticas de incentivo ao mecenato privado, que também ao longo destes dois decénios se generalizaram, assim como, em sentido mais lato, o esforço de evolução no sentido do reforço das medidas de ajuda indirecta, seja com a criação de novas receitas fiscais, como no modelo dos EUA (impostos sobre as dormidas nos hotéis destinados ao financiamento de instituições culturais locais; percent-for-art taxes sobre as receitas do álcool, do tabaco ou do jogo; etc.), seja através da 'invenção' de novas fontes de receitas, como foi o caso da lotaria no Reino Unido, cujos fundos revertem parcialmente, desde a sua criação em 1994, para o financiamento das artes e da cultura, com efeitos que se consideram muito positivos (Creigh-Tyte e Gallimore, 1999) ${ }^{13}$.

\section{ESPECIFICIDADES DO CASO PORTUGUÊS: UM RELANCE SOBRE O PERÍODO PÓS-1986}

Portugal, no confronto com os países europeus, particularmente com os outros Estados membros da UE, apresenta especificidades várias que se prendem com a sua condição semi-periférica, o passado político, e a trajectória económica que seguiu nas últimas décadas.

Comparativamente aos Estados europeus de além-Pirinéus, o processo de modernização da economia portuguesa foi tardio. Em 1960 o principal sector empregador era ainda o primário e os níveis de industrialização e urbanização

12 Sobre a reestruturação do audiovisual na Europa, cf. por exemplo REBELo (1995) e BRITO Henriques e Thiel (2000).

13 A canalização das receitas do jogo para o apoio à cultura não é, em todo o caso, uma inovação recente. Os países escandinavos praticam-na desde os anos 30. Também em Portugal parte das receitas dos prognósticos de jogo é destinada ao Fundo de Fomento Cultural. 
podiam considerar-se baixos, situando-se muito aquém dos valores que já então se observavam na Europa Média e Setentrional. Em parte por isso, a implementação do Estado-Providência acabaria por ser lenta, difícil, e nunca plena. Até aos anos 70, não existe de todo; as primeiras medidas de política social aparecem apenas nos finais dos anos 60, no espírito de abertura do regime de Marcelo Caetano, mas só viriam a ganhar certo significado após o fim do Estado Novo, a partir dos anos 70 (MEdina CARREIRA, 1996). Em parte por isso, em parte porque mesmo hoje continuam a existir diferenças assinaláveis do ponto de vista do desenvolvimento económico, nunca se atingiram os níveis de prestação social que se alcançaram em outros países europeus; por isso alguns autores questionam a aplicabilidade do conceito de Estado-Providência a Portugal (por exemplo, Sousa SANTOS, 1994: 63 e seguintes), e outros chamam a atenção para o facto de configurar, juntamente com a Espanha e a Itália, uma forma particular, não 'madura', periférica, de Estado-Providência (MisHra, 1995, no prefácio à edição portuguesa).

O facto do desenvolvimento do Estado-Providência em Portugal ter sido mais tardio e não ter seguido rigorosamente o caminho que seguiram os regimes da mesma família em outros países mais desenvolvidos, não significa que o Estado seja, por tradição, fraco ou ausente. Pelo contrário: temos uma história de considerável intervencionismo do Estado em diversos domínios, da economia à cultura. Durante décadas, sob o domínio do Estado Novo, a censura controlou moral e esteticamente as artes. Como em outras ditaduras, percebe-se desde cedo uma preocupação do Estado com a cultura, que aliás não se coíbe de a utilizar como instrumento de propaganda e difusão ideológica. Com a revolução de 1974 mudam as orientações do Estado mas mantém-se a sua presença, que, noutros termos, é até reforçada. A vaga das nacionalizações, que atinge diversos sectores da economia, cobre então também em parte a esfera cultural, nomeadamente a imprensa e a rádio, e chega-se a pensar em nacionalizar os teatros e os cinemas ${ }^{14}$. Ao mesmo tempo, inicia-se um processo de crescente envolvimento do Estado no financiamento das artes e da cultura, paralelo ou talvez correlativo do esforço mais vasto de lançamento e consolidação do Estado-Providência.

Os meados dos anos 80 marcam o início de um novo ciclo na vida económica e política portuguesa. A adesão em 1986 à CEE/UE e a eleição, pela primeira vez desde 1974, de um governo com maioria parlamentar absoluta, de centro-direita, adepto de uma política económica liberal, conjugam-se de molde a criar condições favoráveis à reestruturação e modernização das infra-estruturas, da base económica e das instituições, que se traduzem num crescimento da economia, numa recomposição da sociedade e numa reorganização do território (Gaspar, Brito Henriques e Vale, 1998).

14 Para as políticas culturais no período revolucionário e pós-revolucionário, cf. Dionísıo (1993). 
Fundamental neste novo contexto 'crescimentalista' é a emergência e afirmação de uma nova cultura política, favorável ao aprofundamento da economia de mercado, e onde modernização, competitividade, eficiência e rendibilidade se assumem como palavras-chave e propósitos a atingir.

Vejamos como esta nova cultura política se traduziu na política cultural.

A primeira ideia a reter será o facto de, no que concerne os grandes objectivos políticos, não haver rupturas de fundo a assinalar. A análise dos programas de governo, antes e após 1986, aponta para um conjunto de princípios orientadores e metas que, mais ou menos, se mantêm constantes - e são, aliás, similares aos que enunciam os programas das democracias mais desenvolvidas -, tais como a universalidade e democratização do acesso aos bens culturais, a descentralização, a defesa do património e da identidade cultural, ou o estímulo à criação artística (LimA DOS SANTOS, 1998: 66 e seguintes). O entendimento que se faz de cada um destes objectivos, o lugar que ocupam nas prioridades do Estado e as estratégias que se definem para os atingir, isso sim varia, ou pode variar. Em matéria de democratização da cultura, por exemplo, tornar-se-ia perceptível a partir de 1986 - e mais ainda nos anos 90, quando se acentuam os valores do pragmatismo na gestão pública e na regulação do sector das artes - uma mudança de espírito, à luz da qual a questão deixaria de ser vista pelo prisma da necessidade de formar público para as artes, mas sim de criar arte para o público. A mudança causaria mal-estar e suscitaria da parte de certos sectores intelectuais de esquerda indignação e as maiores críticas (Dionísio, 1993).

É portanto no plano das soluções preconizadas, das medidas de política, e, em particular, da forma como se equaciona o papel do Estado e a sua relação com o mercado, que se dão as principais mudanças. À semelhança do que sucede internacionalmente, três tendências maiores começam então a ser perceptíveis: a) a desmonopolização, privatização e liberalização de certos serviços públicos; $b$ ) o reforço das parcerias público-privado e $c$ ) a introdução de critérios comerciais na actividade cultural do sector público.

A desmonopolização e liberalização dos serviços públicos atinge sobretudo o sector dos media. Inicia-se logo na segunda metade dos anos 80 , com a liberalização da rádio, e ganha fôlego após 1989, com a revisão constitucional que permite abrir caminho à desmonopolização do sector da TV e sua consequente abertura aos exploradores privados, que ocorre no início dos anos 90. Mais tarde, já na segunda metade deste decénio, sob o governo socialista, aprofundar-se-ia ainda mais este caminho com a desregulação da TV-cabo.

Fora do sector dos media, a tendência de desestatização/privatização não foi tão evidente, ou tão radical, nem a sua continuidade inteiramente assegurada. Fizeram-se ainda assim alguns ensaios de privatização da gestão de equipamentos. Uma experiência que terá ficado mais próxima do princípio da desestatização/privatização foi a extinção do Teatro Nacional São Carlos (TNSC) em 1992 (que, desde o início dos anos 80, tinha o estatuto de empresa pública) e a sua substituição, em 1993, por uma instituição de direito privado 
- a Fundação São Carlos (FSC) -, à qual ficou acometida a responsabilidade da conservação do teatro, da produção de espectáculos de ópera, e ainda a manutenção da Orquestra Sinfónica Portuguesa e da Companhia Nacional de Bailado. Tendo por sócios fundadores o Estado e algumas empresas públicas e privadas, a FSC deveria seguir um modelo de gestão privado e ter como meta o auto-financiamento. Os resultados desta quasi-privatização não foram, todavia, especialmente animadores, visto que o seu principal contribuinte continuou a ser o Estado. Sob o argumento de que a FSC não era afinal mais do que uma ficção institucional (ou uma forma encapotada de financiamento pelo Estado), voltaria a passar para o sector público - embora com alguma autonomia, sob a forma de instituto - em 1998.

O reforço das parcerias público-privadas, que de certo modo é também o que está em causa na história da FSC, torna-se uma tendência claramente perceptível logo desde 1986, quando é regulada a prática do mecenato privado e são criados incentivos ao seu desenvolvimento no Decreto-Lei n. ${ }^{\circ} 258 / 86$, de 28 de Agosto. Este documento dava a perceber uma nova atitude no financiamento das artes e da cultura, que parecia apontar, tendencialmente (ou idealmente), para um papel menos determinante do Estado, ou até tão-só suplementar.

A busca de novas formas de gestão e financiamento da cultura, baseada nas tais parcerias público-privadas, é perceptível também no facto de ser sob a forma de fundações - ou seja, instituições de direito privado à frente das quais, como fundadores, figura o Estado em parceria com outros organismos, públicos e privados - que aparecem algumas das mais importantes instituições culturais surgidas em Portugal nos anos 90: o Centro Cultural de Belém (Fundação das Descobertas); a Casa de Serralves (Fundação Serralves); ou ainda a Orquestra Metropolitana de Lisboa.

Quanto à terceira tendência que identificámos nas políticas culturais do período pós-1986 - a crescente preponderância dos critérios comerciais, de eficiência e produtividade, na gestão das artes e da cultura - vários sinais podem ser indicados.

Um é a importância que o auto-financiamento, ou pelo menos a capacidade de gerar receitas próprias, começa a ter na filosofia de gestão das instituições culturais, quer nas que assumiram o estatuto de fundações, quer nas que permaneceram inteiramente sob alçada do Estado. Nos museus, por exemplo, como, em certa medida, nos monumentos nacionais, este princípio passou claramente a ser assumido como um critério de boa gestão; e isto não apenas para os responsáveis políticos, como para os próprios profissionais que se encontram à frente das instituições (directores, conservadores, etc.). Também isto explica que os melhoramentos introduzidos nos museus ou nos palácios nacionais, com vista à sua modernização e reequipamento, tenham passado no último decénio a contemplar cada vez mais a criação de espaços de restauração (que têm sucesso) e lojas especializadas, serviços que a experiência internacional demonstra serem formas capazes de diversificar as fontes de financiamento e de gerar receitas próprias. 
Um outro sinal da tendência de crescente intrusão dos princípios comerciais e de eficiência na gestão das artes e da cultura pode ser encontrado nos novos critérios de atribuição de subsídios ao teatro que se definiram no princípio dos anos 90 . Na óptica da máxima eficácia na utilização dos fundos públicos, e também da valorização do princípio da 'arte para o público', os subsídios às companhias passaram a ser concedidos em função de variáveis como a lotação das salas, o número de representações previstas para o projecto em causa, ou as audiências médias obtidas nos anos antecedentes ao concurso. Talvez tenha sido este um dos domínios em que se levaram mais longe os valores do pragmatismo e a lógica comercial ${ }^{15}$. Estes critérios, constituindo um ponto polémico da política cultural, que os sectores intelectuais viam com mal-estar (uma subordinação das artes à lógica das audiências), seria revisto logo em 1996, na sequência da mudança governamental.

A vitória socialista introduz, de resto, a partir de 1995, outras mudanças. Destaca-se em primeiro lugar uma profunda reestruturação orgânica, com a 'promoção' da Secretaria de Estado da Cultura (SEC) a Ministério (MC), e depois, prolongando-se pelos anos seguintes, a criação de vários novos organismos autónomos e institutos, dependentes do MC, especializados. Por outro lado, altera-se o discurso político. $\mathrm{O}$ assumir de um maior intervencionismo do Estado no plano cultural aparece então como uma inerência da esquerda e como uma promessa de diferença face à política dos anos anteriores (CARRILHO, 1999: nomeadamente 33 e seguintes ou 69 e seguintes).

Este regresso à imagem do Estado interventor teve traduções práticas, como ilustra o recuo no processo de desestatização do TNSC, a política de aquisições nas artes plásticas, a instituição de bolsas para os criadores literários, ou a reposição do sistema mais convencional de financiamento do cinema em lugar do sistema de empréstimos aos produtores introduzido na primeira metade dos anos 90. Mas não se abandonaram por inteiro as novas tendências que anteriormente identificámos. Os caminhos do mecenato privado e das novas soluções institucionais baseadas em parcerias entre a administração central, as autarquias e os privados, por exemplo, continuaram a ser explorados (vejam-se os protocolos com as TV privadas para o financiamento do audiovisual, o modelo de gestão do CCB, a política do teatro, etc.). E nem mesmo a via da desestatização parece ter sido inteiramente abandonada, ainda que isso tenha significado nalguns casos contradição com outras medidas antes tomadas... ${ }^{16}$.

A análise da evolução das despesas da SEC/MC ao longo do período em análise contém aspectos que não podem também deixar de ser considerados,

15 É interessante notar como o argumento da melhor utilização dos dinheiros públicos, que em princípio será a justificação para se atribuírem subsídios aos projectos com maior potencial de audiência, serve igualmente para contestar esta opção. Poder-se-á perguntar porquê subsidiar aquilo que o mercado já de si parece capaz de sustentar.

16 O governo socialista teve em estudo uma reestruturação profunda do Teatro Nacional D. Maria II que incluía a possibilidade de extinção da companhia residente. 


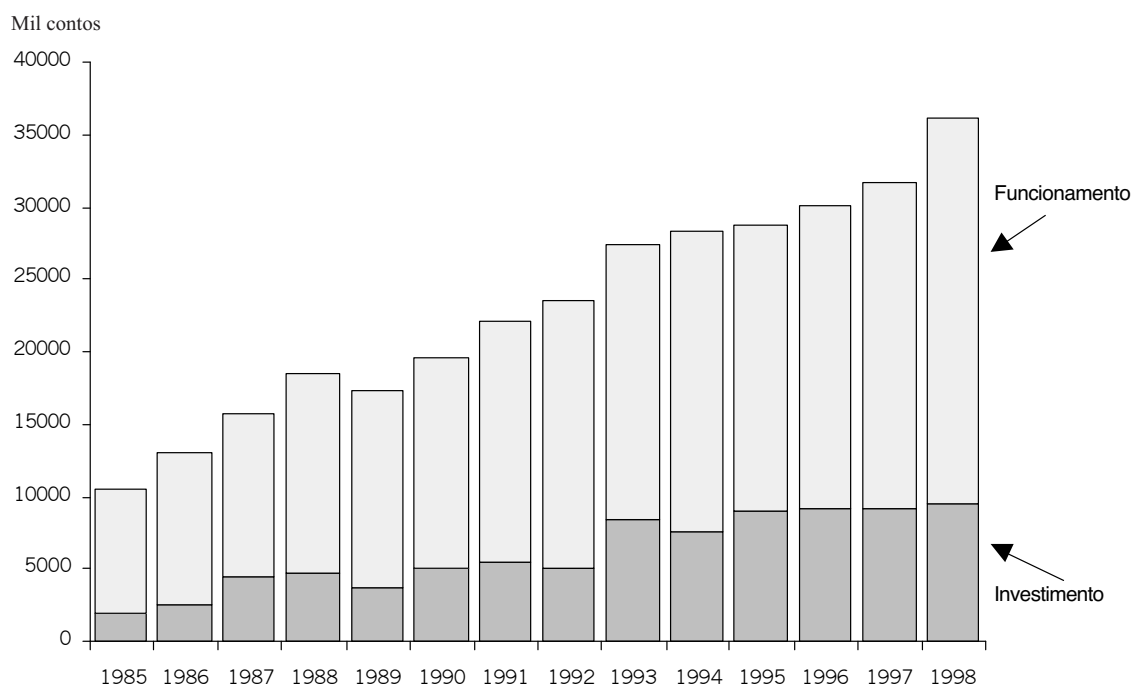

Fonte: Conta Geral do Estado, vários anos.

Fig. 1 - Evolução das despesas públicas de funcionamento e investimento da SEC/MC, 1985-98 (preços constantes de 1998).

Fig. 1 - Ordinary and investment public expenses in culture (SEC/MC), 1985-98 (1998 prices).

pelo menos à primeira vista, contraditórios, e que merecem alguma reflexão (figura 1) ${ }^{17}$.

Globalmente, a tendência pode ser considerada de crescimento, sendo as únicas excepções o ano de 1989, em que os montantes diminuem, e de 1994 e 1995, que globalmente, considerando preços constantes, representam uma estabilização do volume de despesas. O período de 1985 a 1993, que corresponde àquele em que o discurso pró-mercado terá sido mais entusiástico, e a prática liberalizante mais acentuada, acaba por ser também, como se conclui, uma das fases de crescimento mais acelerado das despesas totais da SEC/MC, tendência que aliás seria ainda mais pronunciada caso se considerassem nos números analisados o global das despesas de investimento com o 'conjunto monumental

17 A SEC/MC não esgota todas as despesas da administração central com a cultura. Há diversas funções culturais que estão sob outras tutelas, como sucede com o património (em parte ligado à DGEMN), o Instituto Camões, e vários museus. Segundo Lima dos SANTos (1998: 92), o peso da SEC/MC poderá variar, consoante os anos, entre 50 e $80 \%$, com tendência para aumentar nas datas mais recentes. Mas estas estimativas baseiam-se na classificação funcional (oficial) das despesas do Estado, que levantam algumas dúvidas do ponto de vista conceptual. 
de Belém' - CCB, que só em pequena parte aparecem inscritas nas verbas da tutela da cultura ${ }^{18}$.

O período pós-1995, que na retórica política é marcado, como vimos, por algum criticismo face às medidas de orientação mais liberal e por uma intenção de maior intervencionismo e responsabilização do Estado em matéria cultural, traduz-se num retomar da tendência de crescimento das despesas. Tanto quanto é possível conhecer a partir da fonte utilizada, o crescimento passaria então a fazer-se sobretudo devido à componente das despesas de funcionamento, havendo sinais de estabilização dos gastos em investimento. Isto seria por um lado consequência da opção por uma reorganização e expansão dos serviços e por um aumento dos respectivos quadros (nomeadamente, com a multiplicação de institutos), por outro lado de uma intenção mais clara de apoio e subvenção da criação artística, cujas verbas provêm em boa parte do orçamento de funcionamento.

\section{O CASO PORTUGUÊS E AS TENDÊNCIAS INTERNACIONAIS: PISTAS PARA INTERPRETAR AS DIFERENÇAS}

Que significam afinal as várias mudanças que detectámos internacionalmente no plano das políticas culturais? Que consequências têm ou como devem elas ser entendidas à luz da tradição de intervenção estatal na cultura, patente na generalidade das democracias desenvolvidas? Como relacioná-las em particular com o projecto que se define no Pós-guerra, no quadro dos Estados-providência? Será mais adequado falar a este respeito de ruptura ou de ajustamento a um novo contexto? E como ler, nesse pano de fundo, as especificidades do caso português?

Não há provavelmente sobre isto, por ora, uma resposta sólida que se possa adiantar com firmeza. Assim como não há nenhuma certeza acerca de para onde tende a ir a actuação do Estado em outros domínios, ou sobre o que se passa com o próprio Estado-Providência no seu conjunto, enquanto conceito. Alguns autores insistem mais, ou focalizam-se sobretudo, na mudança. É o caso de JESSOP (1994), por exemplo, para quem as alterações em curso na esfera política traduzem a passagem do Estado-Providência para uma nova forma de Estado, mais schumpeteriano que keynesiano, norteado já não pela questão da redistribuição nem do pleno emprego, mas da competitividade e da inovação. Outros autores, como Mishra (1995), não negando que há mudanças em curso, notam que estas variam de país para país e preferem considerar que traduzem diferentes estratégias de adaptação do Estado-Providência a um novo contexto macro-económico.

18 Note-se que os números citados apenas contemplam a componente do esforço nacional nas despesas de PIDDAC, que para além destas também incluem verbas provenientes do FEDER. O crescimento real das despesas de investimento da tutela da Cultura terá sido portanto ainda mais acentuado do que estes números sugerem. 
Que a tendência internacional vai no sentido de uma maior contenção das despesas públicas na cultura, à semelhança aliás do que sucede em outros domínios, parece ser um facto. Que os privados são cada vez mais convocados a participarem na provisão de bens e serviços culturais e no financiamento das artes, também. Não é seguro, porém, que tal signifique ou seja um prenúncio do fim da intervenção do Estado em matéria cultural, dado que as despesas públicas com a Cultura tendem a permanecer elevadas nas democracias desenvolvidas e não há sequer indícios claros de que, em termos relativos, o seu peso no cômputo geral das despesas do Estado tenha diminuído.

Independentemente, portanto, de a evolução ir no sentido do colapso do Estado-Providência ou tão somente da sua adaptação a um novo contexto, seguro parece ser que as artes e a cultura continuarão a ser, pelo menos no horizonte previsível, objecto de políticas específicas por parte do Estado. Assim como as políticas culturais antecederam a emergência do Estado-Providência, também provavelmente lhe irão sobreviver. Há toda uma tradição de mecenato público com a qual é difícil romper. Parece em todo o caso ser claro, de acordo com a experiência internacional, que as exigências e procuras sociais em matéria cultural não podem continuar a ser asseguradas nos moldes paternalistas tradicionais, dado que há todo um conjunto de novos condicionalismos económicos desfavoráveis à intervenção do Estado, ou que pelo menos aconselham maior comedimento e racionalidade nos recursos afectados. Daí que tenha vindo a ser procurada a resposta num envolvimento mais plural da sociedade.

A originalidade portuguesa neste domínio reside no facto de, contrariamente ao que sucedeu nas democracias mais desenvolvidas, os últimos anos terem sido ainda - como vimos - um período de franca expansão das despesas públicas com a Cultura. Mais se estranha por parecer haver certo desajuste ou discordância entre o que se defende no plano da retórica política, o caminho que parecem indicar algumas medidas tomadas, e depois o que se verifica de facto na evolução dos gastos públicos.

É possível que Portugal, apresentando algum atraso comparativamente às democracias desenvolvidas, e particularmente aos Estados europeus, se encontre numa situação especialmente contraditória. Portugal, sendo um Estado-Providência mais 'jovem', ainda sem os níveis de prestação social nem de envolvimento na cultura alcançados nos Estados-Providência mais 'maduros', estaria ainda, segundo esta interpretação, numa fase de expansão. Conjugar-se-iam assim, na sua evolução, tendências que em outros países ocorreram dissociadamente no tempo: de um lado, uma pressão que incita ao crescimento das despesas, sobretudo devido ao aumento das procuras culturais associado à expansão das classes médias urbanas; do outro, os efeitos de um novo paradigma mais liberal, de um contexto mais favorável aos princípios da responsabilidade partilhada entre Estado e privados, que chega através da experiência dos outros. 


\section{BIBLIOGRAFIA}

Adams, T. (coord.) (1994) - La Politique Culturelle des Pays-Bas. Conseil d'Europe, Estrasburgo.

Brito Henriques, E.; Thiel, J. (2000) - The cultural economy of cities: a comparative study of audiovisual sector in Hamburg and Lisbon. European Urban and Regional Studies, 7 (3): 253-268.

BuRNS, S. (1999) - Talking about a revolution!: the management of change in arts and cultural organisations. In L. Uusitalo e J. Moisander (ed.). Proceedings of $5^{\text {th }}$ International Conference on Arts \& Cultural Management, vol. I. Helsinki School of Economics and Business Administration, Helsínquia: 4-13.

Carrilho, M. M. (1999) - Hipóteses de Cultura. Editorial Presença, Lisboa.

CAUST, J. (1999) - Is the audience more important than the art? The impact of economic rationalist policies on government intervention in the cultural sector, with specific reference to Australia from 1993-1999. In L. Uusitalo e J. MoIsAnder (ed.). Proceedings of $5^{\text {th }}$ International Conference on Arts \& Cultural Management, vol. I. Helsinki School of Economics and Business Administration, Helsínquia: 15-22.

Creigh-Tyte, S.; Gallimore, J. (1999) - The uK National Lottery and the arts: reflections on the lottery's impact and development. In L. Uusitalo e J. Moisander (ed.). Proceedings of $5^{\text {th }}$ International Conference on Arts \& Cultural Management, vol. II. Helsinki School of Economics and Business Administration, Helsínquia: 368-382.

Dionísıo, E. (1993) - Títulos, Acções, Obrigações (A Cultura em Portugal, 1974-94). Edições Salamandra, Lisboa.

Esping-Andersen, G. (1990) - The Three Worlds of Welfare Capitalism. Princeton University Press, Princeton.

Gaspar, J.; Brito Henriques, E.; Vale, M. (1998) - Economic restructuring, social re-composition and recente urban changes in Portugal. GeoJournal, 46: 63-76.

Grampr, W. D. (1991) - Arte, Inversión y Mecenazgo. Un Análisis Económico del Mercado del Arte. Ed. Ariel, Barcelona [versão original: id. (1989) - Pricing the Priceless. Basic Books, Nova Iorque].

Isohokana-AsunmaA, T. (coord.) (1996) - La Politique Culturelle de la Finlande. Conseil d'Europe, Estrasburgo.

Jessop, B. (1994) - Post-Fordism and the state. In A. Amin (ed.). Post-Fordism. A Reader. Basil Blackwell, Oxford e Cambridge: 251-279.

Kleberg, C. J. (coord.) (1992) - La Politique Culturelle Nationale de la Suède. Conseil d'Europe, Estrasburgo.

Lima dos Santos, M. L. (coord.) (1998) - As Políticas Culturais em Portugal-Relatório Nacional. Observatório das Actividades Culturais, Lisboa.

Medina Carreira, H. (1996) - As políticas sociais em Portugal. In A. Barreto (coord.). A Situação Social em Portugal, 1960-1995. Instituto de Ciências Sociais, Lisboa.

Mishra, R. (1984) - The Welfare State in Crisis. Wheatsheaf Books, Brighton.

Mishra, R. (1995) - O Estado-Providência na Sociedade Capitalista. Estudo Comparativo das Políticas Públicas na Europa, América do Norte e Austrália. Celta Editora, Oeiras [versão original: id. (1990) - The Welfare State in Capitalist Society. Policies of Retrenchment and Maintenance in Europe, North America and Australia. Harvester Wheatsheaf, Londres]. 
Mónica, M. F. (1999) - O estado e a cultura. In id., Cenas da Vida Portuguesa. Quetzal Editores, Lisboa, 2. ${ }^{\mathrm{a}}$ ed.: $69-79$.

Mulcahy, K. V. (1997) - The government and cultural patronage: a comparative analysis of cultural policymaking in the United States, France, Norway, and Canada. Comunicação apresentada à Annual Conference on Social Theory, Politics and the Arts, 2-4 de Outubro. Kennedy Space Center, Florida [não publicado, cedência do autor].

Netzer, D. (1978) - The Subsidized Muse. Public Support for the Arts in the United States. Cambridge University Press, Cambridge e Nova Iorque.

Peck, J.; Tickell, A. (1994) - Searching for a new institutional fix: the after-Fordist crisis and the global-local disorder. In A. Amin (ed.). Post-Fordism. A Reader. Basil Blackwell, Oxford e Cambridge: 280-315.

Raussel Köster, P. (1999) - Políticas y Sectores Culturales en la Comunidad Valenciana. Um Ensayo sobre las Tramas entre Economía, Cultura y Poder. Universitat de València, Valência.

Rebelo, J. (1995) - Os caminhos sinuosos do audiovisual na Europa. Vértice, 67: 67-72.

Sobral, J. M. (1996) - Nações e nacionalismo. Algumas teorias recentes sobre a sua génese e persistência na Europa (Ocidental) e o caso português. Inforgeo, 11: 13-41.

Sousa Santos, B. (1994) - Pela Mão de Alice. O Social e o Político na Pós-modernidade. Ed. Afrontamento, Porto.

Zimmer, A.; Toepler, S. (1996) - Cultural policies and the Welfare state: The cases of Sweden, Germany, and the United States. The Journal of Arts Management, Law, and Society, 26 (3): 167-193.

Zimmer, A.; Toepler, S. (1999) - The subsidized muse: government and the arts in Western Europe and the United States. Journal of Cultural Economics, 23 (1-2): 33-49. 